\title{
TQMIS: The Relationship between Total Quality Management and Information Systems
}

\author{
Fatimah Alqahtani $^{1}$, Nouf Alghrair ${ }^{2}$, Azrilah AbdAziz ${ }^{3}$ \\ Information Systems Department, Faculty of Computing \& Information Technology, King Abdulaziz University, \\ Jeddah, Saudi Arabia ${ }^{1,2}$ \\ $\mathrm{PhD}$, Information Systems Department, Faculty of Computing \& Information Technology, King Abdulaziz University, \\ Jeddah, Saudi Arabia ${ }^{3}$
}

\begin{abstract}
In recent years, the total quality management information systems (TQMIS) aims to extract high quality information, collect, store and manipulate information. The total quality management information systems contains several databases. Therefore, TQMIS leads to increasing customer satisfaction, increasing employee productivity and improving the quality of products or services provided. TQMIS enhances the organization and considers a competitive advantage. In this work, we conducted an overview of the total quality management information systems.
\end{abstract}

Keywords: TQMIS, TQM, IS, CRUT-Model, ITEC.

\section{INTRODUCTION}

Total quality management (TQM) is a management theory or a way that identified by assumptions, rules, and methods that highlight a system's responsibilities of the client and extended development of every process by using data-driven, problem-solving methods depending on top management commitment and empowerment of employee groups [1]. Total Quality Management has many definitions, all of them aim to enhance productivity, focus on quality and minimize defects as much as possible in the product or service provided [16]. TQM aims not only to present the basis of a steadily developing a system but also seeks to ensure aggressive and stable standing through constantly developing quality. A system can have excellent production if it has high quality. TQM philosophy has five fundamental rules: top management commitment, customer focus, continuous improvement, structured problem-solving processes, and employee empowerment [1]. It is possible to determine the measurement of the implementation of the total quality management by three dimensions: TQM program use, perceived influence and TQM understanding [14]. "TQM is an information intensive management. Information plays a vital role as all quality improvement activities are based on informed decision-making" [17].

In fact, TQM and Information Systems have common objectives. Some of the fundamental objectives of TQM in most organization is to develop the quality of the products and operations to satisfy both consumer and organization members needs as well as increasing competitiveness and effectiveness. While Information Systems objectives are: growing production, developing quality, improving services, declining costs, and increasing the organization's competitiveness [14]. In this work, we will view total quality management (TQM), total quality management information systems (TQMIS), how TQM and IS are related and integrated, and CRUT-Model.

\section{TOTAL QUALITY MANAGEMENT TRADITIONAL ELEMENTS}

Even though TQM has many definitions, most of these terms that have done by several researchers have a single approach that concentrated on developing whole the organization continuously to improve the product quality and increase services to obtain customer and team members satisfaction [15]. The characteristics and forms of TQM vary according to the objectives of the organization, and the quality requires continual improvement to gain and achieve customer satisfaction [16]. In this part will explain TQM aspects and how they enforced in the organizations. Total quality management ask the top management of the organizations to enforce organized and convincing analysis. Ethics, integrity, trust, training, teamwork, leadership, recognition, and communication are the aspects of TQM. Fig. 1. demonstrates how TQM aspects are linked to each other.

The left side includes aspects that show how well an organization is involving to corporate social responsibility. The right side contains characters that show how an organization's members and administrator achievement provide the organization's quality of services. The recognition and communication aspects describe how organization's members and executive achieve an organization's objectives. The administration can apply TQM by using the information at the end of the two sides correctly [2]. 


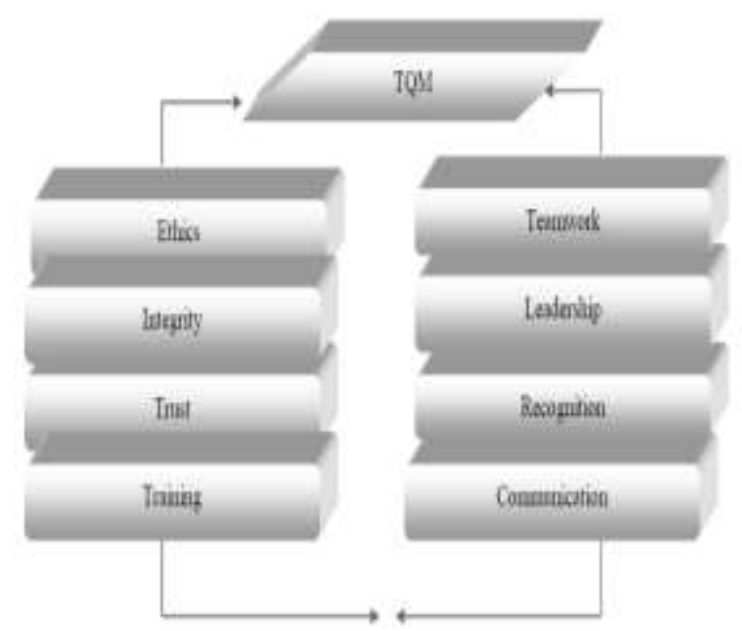

Fig. 1. Conceptual Model of Traditional Total Quality Management

\section{III.TOTAL QUALITY MANAGEMENT INFORMATION SYSTEMS}

What is Information Systems? Practically entire organizations in both private and governmental sectors use several shapes of the technology-based information system to assess decision-making operations. Technology-Based information system became an essential element for success an organization. IS includes two distinct parts:

- $\quad$ Obtaining, expanding and controlling technology-based systems in business, government and other agencies.

- Designing, improving and achieving technology-based systems.

IS acts as a link between the current evolution of essential kits and the adoption of those packages [3]. Siam et al. demonstrate that TQM achievement takes advantages of IT further in the 'information and analysis,' 'output quality assurance,' the 'important innovation,' the 'customer satisfaction,' the 'leadership' and the 'strategic planning process.' Among the benefits of TQMIS: increasing customer satisfaction, increasing employee productivity and improving the quality of products or services provided [8]. Total quality management can be applied to the information system because it improves the quality of the product or service and contributes to the development and improvement of the information system. TQMIS aims to monitor and manage quality as it meets the objectives and strategies of the organization in the long term. It relies on information integration technology, and from this system can extract highquality and useful information [7]. TQMIS deals with an important and complex information, updates, retrieves, and processes the information. This considered as database management system for collecting and storing information. TQMIS was designed to contain six distinct databases: management database, customer database, design and engineering database, inspection and control database, maintenance database and production planning \& scheduling database as shown in Fig. 2. So, TQMIS is a fundamental element of the success of TQM in the organization [9].

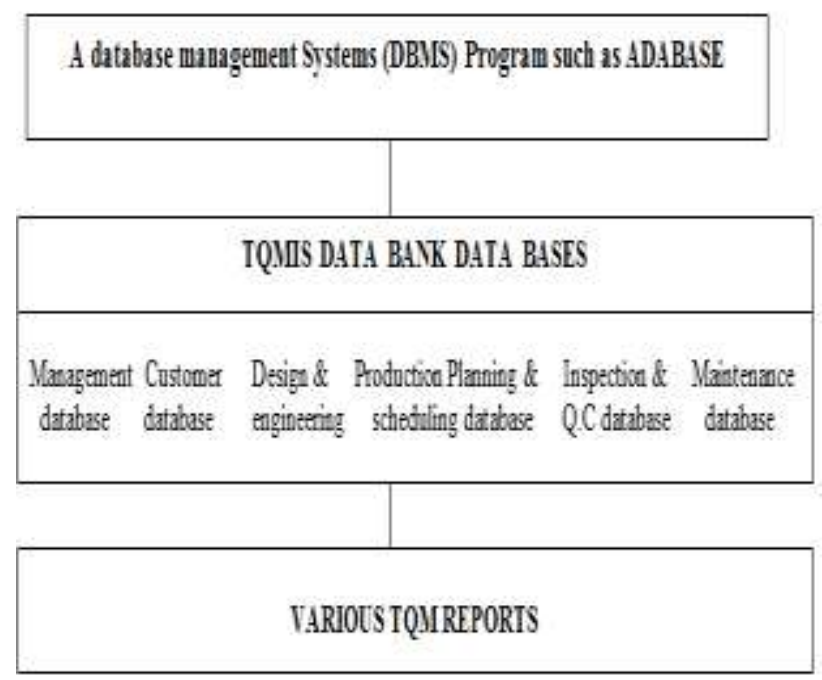

Fig. 2. Conceptual Model of Traditional Total Quality Management 


\section{IV.ESTABLISHING THE LINK BETWEEN INFORMATION SYSTEMS AND TOTAL QUALITY MANAGEMENT}

TQM is information demanding, that information to be saved is required serious. Plenty TQM applications have not success to fulfil long-dated crucial goals because of the shortage connection between IS and TQM. IS unit engages in TQM beginning might concentrate on using quality tools just to manage and develop their objectives regardless their actual engaging to the accomplishment of TQM achievement? To overpass that hole and to connect IS and TQM, a framework was established. The structure demonstrates that IS and TQM have shared goals, elemental ideas, and administration arrangements. Efficient designing and application of each are crucial factors to accomplishments. They are adaptable and able to be joined into one pattern to increase the competitive status of an organization as shown in Fig. 3. [4].

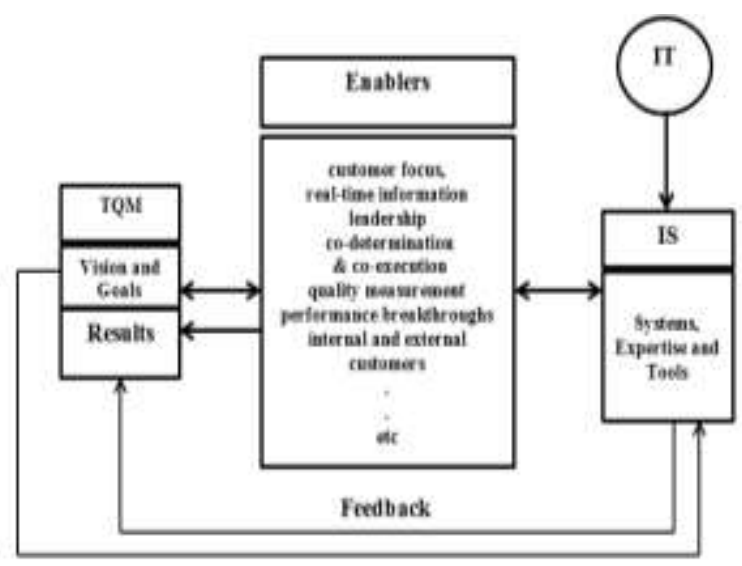

Fig. 3. IS-TQM Framework

\section{THE RELATIONSHIP BETWEEN TQM AND IS}

Kate illustrates that TQM and IS need each other to do their responsibility even though they have full various responsibility. TQM needs information systems (information) as a feedback to do its job and to guarantee the proper information is exist, and the right decision can be taken, IS requires TQM. In the organizations that are depending on TQM, the role of IS is to supply the right information and does not participate in specifying duty, manage or decisionmaking. This is called TQMIS (Total Quality Management Information Systems). The concept of quality is important in maintaining information systems but not that most importance in IS. So, Both TQM and IS are integrated and get along with each other within the organization [5]. Flexibility and adaptability to the needs of the organization should be available in the TQM system, which is based on analysing the activities of the departments and providing opportunities for their development and improved. The total quality management system can be built by individual or group planning [10]. TQM team consists of: Quality Council, Quality Control Teams, Quality Process Teams, Quality Workshops, and the participation of all organization's employees [11]. The implementation of TQM is aimed to improving quality to increase Effectiveness, efficiency and to achieve a high level of development [12]. Their application is a competitive advantage and enhances the organization's performance [13]. The TQM system can also be implemented to predict the future and solve the problems that are expected to occur [10].

\section{VI.INFORMATION SYSTEMS MAINTENANCE: THE APPLICATION OF TOTAL QUALITY MANAGEMENT CONSTRUCT: CRUT-MODEL}

CRUT components are linked with each other. The control component is a crucial one in the model because it is essential to manage and control the IS in the organization. Besides that, the other components, reliability, user participation, and training are engaging in IS managing as shown in Fig. 4. [6]. CRUT model helps the organizational executive to protect IS quality, and IS improvement have an effect on a quality preserve. CRUT model contains control, reliability, user participation, and training, which can help the organizational executive in selecting the right IS for their company. IS builder will have the responsibilities for managing and preserving the IS that they built. The corporate executive can choose the proper system by applying control in the company. IS reliability addresses the value of the scheme as well as the issues immediately. Besides that, taking into account that how both IS users and builders can get advantages of IS improvements including different exercises. The TQM aspects, which consist of integrity, training, employee involvement, and customer focus (ITEC), would help the executive of the company to preserve different systems within an organization as well as manage and protect systems from illegal end users [6]. 


\section{IARJSET

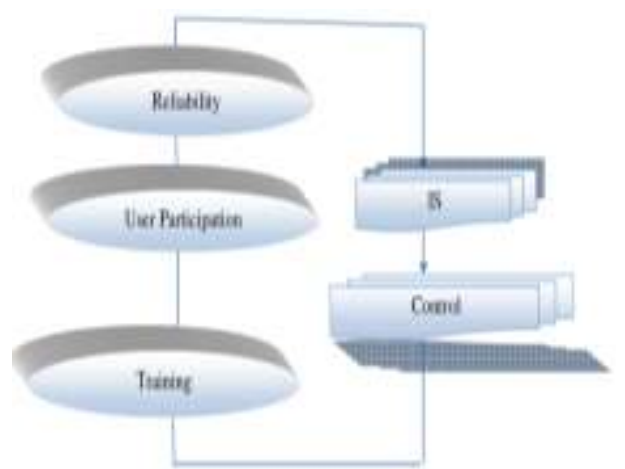

Fig. 4. CRUT-Model

\section{CONCLUSION}

TQMIS aims to monitor and manage quality as it meets the objectives and strategies of the organization in the long term. In this paper, we introduced a brief introduction to total quality management and its traditional Elements. We illustrated Total Quality Management Information System which relies on information integration technology, and from this system can extract high-quality and useful information. Afterward, demonstrating the link between Information Systems and Total Quality Management in IS-TQM framework. The structure of this framework shows that both IS and TQM have equivalents objectives, ideas, and administration arrangements. Based on that, the framework joins both IS and TQM in one structure to accomplish the organization goals as well as to increase its competitive status. Despite that IS, and TQM have different accountability, they still need each other to achieve their responsibility. CRUT-Model has been illustrated although which helps the organization to select the proper system, while TQM aspects would help organization executive to preserve different systems within an organization as well as manage and protect systems from illegal end users.

\section{REFERENCES}

[1] Cheon, Myun Joong, and Antonis C. Stylianou. "Total quality management for information systems: an empirical investigation." Journal of Global Information Technology Management 4.4 (2001): 32-52.

[2] Urhuogo, Irikefe, and Harish C. Chandan. "Information Systems Effectiveness: The Application of Corporate Social Responsibility Policy and Total Quality Management Model." Journal of Business Studies Quarterly 4.1 (2012): 181.

[3] Siam, Ahmad Z., Khalid Alkhateeb, and Sami Al-Waqqad. "The role of information systems in implementing total quality management." American Journal of Applied Sciences 9.5 (2012): 666.

[4] Khalil, Omar EM. "Information systems and total quality management: establishing the link." Proceedings of the 1994 computer personnel research conference on Reinventing IS: managing information technology in changing organizations: managing information technology in changing organizations. ACM, 1994.

[5] Ho, Kate. "Differing roles of Information Technology (IT) between Total Quality Management (TQM) and Information System (IS) based organisations: Using accountability as an explanation."

[6] Urhuogo, Irikefe, Valerie Vann, and Harish C. Chandan. "Information Systems Maintenance: The Application of Total Quality Management Construct." Journal of Business Studies Quarterly 3.3 (2012): 1.

[7] Rahman, Zillur, and Jamshed Siddiqui. "Exploring total quality management for information systems in Indian firms: application and benefits." Business Process Management Journal 12.5 (2006): 622-631.

[8] Wang, Xiaoh. "The Realization of Knowledge Discovery in Total Quality Management System." Fuzzy Systems and Knowledge Discovery, 2008. FSKD'08. Fifth International Conference on. Vol. 4. IEEE, 2008.

[9] Bandyopadhyay, J. "A total quality management information system for auto parts manufacturers in the United States." International Journal of Management20.2 (2003): 187.

[10] Larina, Ludmila N. "Practical application of Total Quality Management system to education of international students." Procedia-Social and Behavioral Sciences 215 (2015): 9-13.

[11] Taskov, Nako, and Elizabeta Mitreva. "The motivation and the efficient communication both are the essential pillar within the building of the TQM (total quality management) system within the Macedonian Higher Education Institutions." Procedia-Social and Behavioral Sciences 180 (2015): 227-234.

[12] Mitreva, Elizabeta, and Nako Taskov. "Projection and Implementation of Total Quality Management Systems within the Textile Production." Verslo Sistemos ir Ekonomika 4.1 (2014).

[13] Tabe, Hamid Reza, Hamid Reza Rezaeekelidbari, and Mehrdad Goudarzvand Chegini. "The role of implementation total quality management system on performance in Saipa group companies." Kuwait Chapter of the Arabian Journal of Business and Management Review 3.4 (2013): 25.

[14] Fok, Lillian Y., Wing M. Fok, and Sandra J. Hartman. "Exploring the relationship between total quality management and information systems development." Information \& Management 38.6 (2001): 355-371.

[15] Ghazzawi, Amani, Amjad Alharbi, and Azrilah Abd Aziz. "TQM in E-Commerce: Issues, Implementation and Challenges."

[16] Mohammed, Khadijah, Bashayer Ali Alotibie, and Azrilah Abdulaziz. "Total Quality Management in Saudi Higher Education." International Journal of Computer Applications 135.4 (2016): 6-

[17] Terziovski, Mile, Amrik Sohal, and Danny Samson. "Best practice implementation of total quality management: multiple cross-case analysis of manufacturing and service organizations." Total Quality Management 7.5 (1996): 459-482. 